\title{
Magnetic tape operating systems for the PDP-8*
}

\author{
MICHAEL R. MURPHY \\ Department of Chemistry
}

and

SAMUEL L. MOISE, JR.

Space Biology Laboratory, Brain Research Institute

University of California, Los Angeles, California 90024

A magnetic tape operation system (TMS) based on Digital Equipment Corporation's $4 \mathrm{~K}$ disk monitor system (DMS), but reconfigured to improve speed and performance on a magnetic tape, is described. The TMS is compared in organization to the DMS configured to run from DECtape. A magnetic tape system device handler for Digital Equipment Corporation's OS-8, to allow this operating system to be run from magnetic tape, is included.

An investigator with limited funds must spend his money on equipment which will enhance his data collection system. For many applications, a disk or special-purpose magnetic tape (such as DECtape or LINCtape) are not necessary for experimental control or data acquisition. A typical configuration might include $4 \mathrm{~K}$ of core, A-D converters, a real-time clock, sense lines, a relay buffer, and an industry-compatible magnetic tape (usually 9-track). The last item, while relatively expensive, is often necessary for the further reduction of large amounts of data, usually done with larger computers. Special-purpose tape drives such as DECtapes cannot be read on most commonly available larger computers (e.g., IBM 360, Univac 1108).

Unfortunately, without a disk or DECtape, the user is unable to run either of Digital Equipment Corporation's (DEC) monitor systems - the disk monitor system (DMS) or OS-8. This leaves the user in the time-consuming and difficult position of developing what may be a large amount of software with only a paper-tape system (high-speed, if he is fortunate). It is desirable for the user with an industry-compatible magnetic tape to have the power of an operating system available to help write. assemble, debug, and store programs.

There are several magnetic tape systems available for the PDP-8, but none that we are aware of approaches the utility and power of either of DEC's monitor systems. To meet the need of several users in the Los Angeles area, we have reconfigured and modified the 4K DMS (DEC, 1970) to run for any 7 - or 9-track magnetic tape system that is instruction-compatible with DEC's TC-58 controller and TU20 or TU10 tape drive. Since creating our system, a paper by Custer (1969) appeared which describes an earlier modification of the DMS to run from

*This research was supported in part by U.S. Public Health Service Grant GM 16058, AFOSR Contract F 44620-70-C-0017, and NASA Grant NGR 05-007-195. a single industry-compatible magnetic tape. Custer's system anticipated ours in some respects, but it does not seem to have the same speed or the improved format. Operation of our system is completely compatible with the disk system with a few exceptions.

\section{FORMAT AND BOOTSTRAP}

The tape format we use is similar to that described by Custer (1969) and is depicted in Fig. 1. The 3-in. gap preceding each EOF has been a crucial feature of all random-access tape systems because of the necessity for protecting records (particularly EOF) against "slop" at the end of a write operation. With very precise tape drives such as DEC's TU20 or TU10, the long gap is not necessary. To go from one TU20 or TU10 to another on a different system, however, requires a long gap since no two tape drives are precisely aligned. Less precise tape drives require the 3 -in. gap in order to operate at all.

The bootstrap is a 128-word record (1 page) immediately following the load reflector on the tape. The toggle loader to read in this record is six locations shorter than the standard DECtape bootstrap. When started, this loader reads the bootstrap record into core, starting at Location $\emptyset 2 \phi \emptyset$, and then transfers to that location. The bootstrap then reads Block $\phi$, which contains the system I/O routine (see Fig. 2) into Locations $1200-1377$, relocates it to $7600-7777$, and transfers to 7600 . Operation is then the same as a system

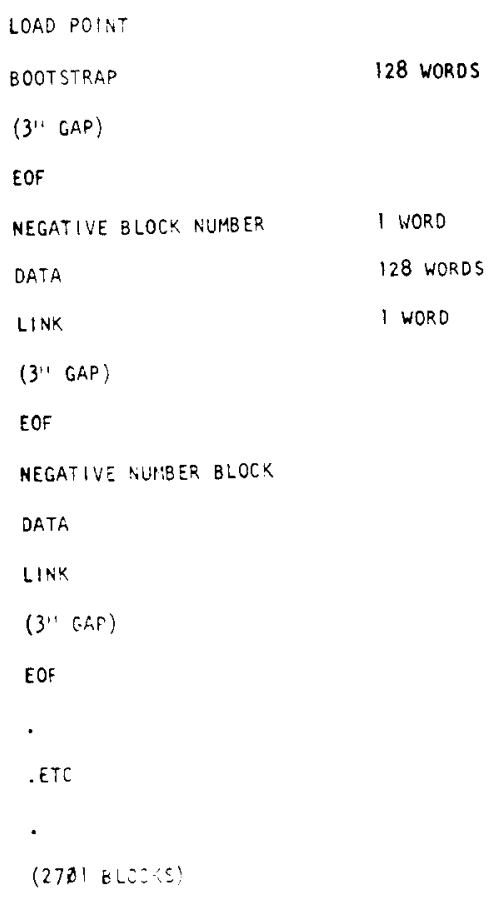

Fig. 1. Tape format for the tape monitor system. 


\begin{tabular}{|c|c|c|c|}
\hline BLOCK & TAPC MONITOR & DEC TAPE & \\
\hline 0 & MONITOK HEAD & MONITOR HE & HEAO \\
\hline $\mathbf{i}$ & SCẼATCH : & SAVE 1 & \\
\hline 2 & MONITOR 1 & MONITOR I & 1 \\
\hline 3 & SCRATCH 2 & OH (BACKUP & P) \\
\hline 4 & SAVE 1 & SAM (BACKU & (UP) \\
\hline 5 & MONITOR 2 & SCRATCH 1 & \\
\hline 6 & GET I (REPLACES CALL I) & SCRATCH 2 & \\
\hline 7 & SCRATCH 3 & SCRATCH 3 & \\
\hline 10 & SALE 2 & CALL 2 & \\
\hline 11 & SAVE 3 & SAVE 3 & \\
\hline 12 & SAVE 4 & SAVE 2 & \\
\hline 13 & LOAD I & CALL I & \\
\hline 14 & LOAD 2 & SAVE 4 & \\
\hline 15 & LOAD 3 & $\angle O A D I$ & \\
\hline 16 & LOAD 4 & LOND 2 & \\
\hline 17 & LOAD 5 & LOAD 3 & \\
\hline 20 & LOAD SCR I & COMMAND DE & DECODER I \\
\hline 21 & LOAD SCR 2 & COMMAND DE & DECODER 2 \\
\hline 22 & LOAD SCR 3 & COMMAND DE & DECODER 3 \\
\hline 23 & LOAD SCR 4 & COMMAND DE & DECODER 4 \\
\hline 24 & RESER VED & COMMAND DE & DECOOER 5 \\
\hline 25 & FOR & COMAND D & DECODER 6 \\
\hline 26 & FUTURE & & \\
\hline 27 & EXPAN- & & \\
\hline 30 & SION & $\dot{.}$ & \\
\hline 31 & CONHAND DECOOER I & $\dot{.}$ & \\
\hline $\begin{array}{l}32 \\
33\end{array}$ & $\begin{array}{l}\text { COMMAND DECODER } 2 \\
\text { COMMANO DECODER } 3\end{array}$ & $\ddot{\xi}$ & \\
\hline 34 & COMMAND AFCONER 4 & E్ & \\
\hline 35 & COMYAND DECOOER 3A & 8 & \\
\hline 36 & COMMANO DECODER 5 & $\stackrel{2}{a}$ & \\
\hline $\begin{array}{l}37 \\
40\end{array}$ & CONMAND DECODER 6 & $\div$ & \\
\hline $\begin{array}{l}40 \\
41\end{array}$ & ON 1 & & \\
\hline $\begin{array}{l}41 \\
42\end{array}$ & San 1 & $\stackrel{0}{0}$ & \\
\hline $\begin{array}{l}42 \\
43\end{array}$ & DN 2 & : & \\
\hline $\begin{array}{l}43 \\
44\end{array}$ & $\begin{array}{l}\text { DN } 3 \\
\text { SAM } 2\end{array}$ & $\bar{E}$ & \\
\hline $\begin{array}{l}44 \\
45\end{array}$ & $\begin{array}{l}\text { SAM } 2 \\
\text { SAH } 3\end{array}$ & 3 & \\
\hline $\begin{array}{l}45 \\
46\end{array}$ & $\begin{array}{l}\text { SAH } 3 \\
\text { SAH } 4\end{array}$ & \& & \\
\hline 47 & $\begin{array}{l}\text { SAM } 4 \\
\text { SAM } 5\end{array}$ & - & \\
\hline 50 & GET 2 (REPLACES CALL 2) & - & \\
\hline $\begin{array}{c}1 \\
177\end{array}$ & $\sim$ & & \\
\hline $\begin{array}{l}177 \\
200\end{array}$ & : & DN 1 & \\
\hline $\begin{array}{l}200 \\
201\end{array}$ & : & SAM 1 & \\
\hline $\begin{array}{l}201 \\
202\end{array}$ & & DN 2 & \\
\hline 202 & 0 & SAM 2 & \\
\hline 203 & - & SAH 3 & \\
\hline 204 & $\div$ & $\operatorname{san} 4$ & \\
\hline 205 & 28 & SAM 5 & \\
\hline $\begin{array}{l}206 \\
207\end{array}$ & $=\frac{2}{0}$ & SAM 6 & \\
\hline 207 & 8 & DH 3 & \\
\hline
\end{tabular}

Fig. 2. System layouts for the tape monitor system and the disk monitor system as configured on DECtape.

restart at 7600 . To aid troubleshooting when the system does not bootstrap properly, the bootstrap will halt after relocating Block $\emptyset$ to $76 \emptyset \emptyset$ if the switch register is set to all $\emptyset$ s.

\section{THE SYSTEM}

The tape monitor system (TMS) has been configured to improve speed and efficiency on magnetic tape. Figure 2 shows the TMS layout as compared with the DMS when configured on DECtape.

The system I/O routine, when entered at 7600 , rewinds the tape, writes $74 \varnothing \emptyset-7577$ on Scratch 1 , reads Monitor 1 into that page, and transfers to $740 \emptyset$. Monitor 1 then writes $72 \varnothing \emptyset .7377$ on Scratch 2, reads Save 1 into those locations, reads Monitor 2 in over itself (74ф 0.7577$)$, and transfers to $74 \emptyset \emptyset$. Monitor 1 performs part of the function of the standard $\mathrm{I} / \mathrm{O}$ routine for disk or DECtape and allows space in the system $\mathrm{I} / \mathrm{O}$ routine for a tape rewind. In addition, sequencing these operations in this manner nearly doubles the speed of reading in the monitor over the DECtape arrangement.

SAVE (routines for saving core images) has been arranged sequentially, as has LOAD (routines to load binary files) and the COMMAND DECODER. The scratch blocks for LOAD immediately follow it (Blocks 20-23) to minimize access time once LOAD is started. Since GET 1 (routines to load a saved file) looks at the directory before going to GET 2, GET 1 precedes the directory while GET 2 follows the last SAM block (Block 50). These changes are designed to keep the tape moving in one direction as much as possible. While this arrangement may not be optimal, it speeds overall system operation by a factor of two or more over the conventional DECtape layout.

Perhaps the most important system configuration change is the relocation of directory and SAM blocks from Blocks $177-207$ to $40-47$. It is commonly assumed that a tape directory should be located in the physical center of the tape to minimize access times. To truly minimize system access times, however, the directory should probably be located near those tape resident routines which access it most frequently. The TMS can generally access the front of the tape with a rewind much faster than any other given position. Therefore, the system routines and directory should be located near the beginning of the tape. This directory location becomes cumbersome, however, when editing files which exist a long way down the tape, because for nearly every full buffer the 4K DMS EDITOR writes, the directory and SAM blocks must be accessed and written. In general, however, we have found the system to work 5 to 10 times faster with the relocated directory.

\section{ADDITIONAL SYSTEM SOFTWARE}

We have modified most of the DEC 4K DMS system software to run with the TMS. Use of system programs is exactly as described in DEC's manuals, with the exceptions mentioned above. The EDITOR (DEC, 1970) has been modified to use any available magnetic tape unit or reader for input files and any available output device for output. Pip (DEC, 1970), Pal-D (DEC, 1970), and 8K Pal-D (Conley, 1970) have been modified to work with multiple units. In addition, a utility (ZAP8) written for a disk system has been modified to work with the TMS and allows reading, editing, and writing of any block on any unit. FORTRAN is not supported in this version of the TMS.

\section{MULTIPLE MAGNETIC TAPE UNITS}

All $\mathrm{I} / \mathrm{O}$ is done at $800 \mathrm{bpi}$ in odd parity and core dump mode. DEC's TC58 controller ignores the core dump bit for 7-track drives, allowing the same instruction to operate 7 - and 9-track tapes without modifying the system $1 / O$ routine. It should be noted that at 800 bpi, the TU20 (7-track drive) must be kept meticulously clean to operate without parity errors. For 
single 7-track tape systems, operation at 556 bpi is less likely to produce these errors.

Our system is presently operating on a PDP-8/I with one 7. and one 9-track DEC magnetic tape, a single 7-track tape PDP-8/I system, and two 9-track tape systems (one is a Daconics dual 9-track system on a PDP.8/I, the other is a DEC TU10 on a PDP-8/e). Unit $\emptyset$ is always the system device and must be referenced as $\mathrm{S} \emptyset$ : or $\mathrm{M} \emptyset$; , not $\mathrm{S}$ : as in the DMS. Other units may be referenced as $S N$ : or $M N:(1 \leqslant N \leqslant 7)$.

\section{OS-8 MAGNETIC TAPE SYSTEMS}

For users with at least $8 \mathrm{~K}$ of core and a magnetic tape unit, OS-8 (DEC, 1972) offers a powerful potential alternate to the TMS. Recently, MRM has created and installed magnetic tape system, directory, and sequential device handlers for OS-8. Because of extensive overlaying and swapping, setup time for OS-8 system programs (Editor, $\mathrm{Pal} 8$, etc.) is long compared to the TMS. However, due to the way files are stored (contiguously in the largest free space available), once these programs are ready to go, they operate much faster than equivalent TMS systems software, since they make full use of $8 \mathrm{~K}$ of core and the directory does not have to be accessed again until the end of the job.

On a two-magtape system, OS-8 is, in the long run, comparable in speed to the TMS and offers many more features. In particular, FORTRAN is immediately available. For the single tape user with $8 \mathrm{~K}$ of core, the TMS would appear to be more useful unless the user is prepared to wait a very long time for systems programs to set up. FORTRAN on a single tape system is very slow indeed.

\section{AVAILABILITY}

The operating system, including the tape formatter, system software, and ZAP8 is available from the authors. Those interested should send one $24 \phi \emptyset \mathrm{ft}$ tape (tested at $800 \mathrm{bpi}$ ) and specify 7 - or 9-track operation. Anyone interested in the OS-8 system, directory, or sequential handlers should write the authors also.

\section{REFERENCES}

Conley, C. H, 8K PAL-D assembler for 4K disc monitor system. Digital Equipment Corporation, Maynard, Massachusetts, 1970. DECUS Program No. 8-333.

Custer, D. C. A disc simulator using a single industry standard magnetic tape unit. Decus Proceedings, Fall 1969, pp. 285-289.

DEC. Disc monitor system. Digital Equipment Corporation. Maynard, Massachusetts, 1970, Manual DEC-D8-SDAB-DN.

DEC. OS-8 user's manual. Digital Equipment Corporation, Maynard, Massachusetts, 1972, Manual DEC-S8-OSUMA-A-D.

(Received for publication January 4, 1973; revision received February 24, 1973.) 